\title{
Aula de campo no ensino de Ciências: possibilidades interdisciplinares para a Educação Ambiental
}

\author{
Field class in Science teaching: interdisciplinary possibilities for Environmental \\ Education
}

\author{
Clase de campo en la enseñanza de las Ciencias: posibilidades interdisciplinarias \\ para la Educación Ambiental
}

\author{
Mariana Silva de Andrade ${ }^{1}$ \\ Aline Viégas ${ }^{2}$ \\ Eduardo Folco Capossoli ${ }^{3}$
}

\begin{abstract}
Resumo
Este trabalho é parte de uma pesquisa de pós-graduação (stricto sensu) realizada com estudantes do $6^{\circ}$ e $7^{\circ}$ ano de uma escola privada do município de Nova Iguaçu (RJ). Com o objetivo de identificar possibilidades interdisciplinares de trabalhar a Educação Ambiental nas aulas de campo, a partir do ensino de Ciências, realizamos uma pesquisa-ação, com abordagem qualitativa. Os dados foram coletados durante as aulas anteriores e posteriores às aulas de campo, por meio da gravação em áudio e das produções realizadas pelos estudantes. Esses dados foram analisados à luz da Análise de Conteúdo de Bardin. Através da análise dos dados, percebe-se que a visita aos locais da aula de campo suscitou a mobilização de conhecimentos, de diversas áreas, voltados para a compreensão da realidade socioambiental observada. Tal mobilização contribuiu para a construção de uma concepção crítica da Educação Ambiental.
\end{abstract}

Palavras-chave: Educação Ambiental. Aula de campo. Ensino de Ciências. Interdisciplinaridade.

\begin{abstract}
This work is part of a graduate research carried out with 6th and 7th grade students from a private school in the municipality of Nova Iguaçu (RJ). In order to identifying interdisciplinary possibilities related to the Education in field trips from Science teaching we conducted research-action, with a qualitative approach. The data were collected during the classes before and after the field trip through audio recording and also through the academic productions made by the students. All of these data were treated and analyzed using Bardin's Content Analysis. Based on the analysis of the data, we have realized that the visit to the sites of the field trip led us to the mobilization of knowledge from different areas aimed to understanding the socio-environmental reality. Such a mobilization contributed to the construction of a Critical conception of Environmental Education.
\end{abstract}

Keywords: Environmental Education. Field trip. Science teaching. Interdisciplinarity.

\section{Resumen}

Este trabajo es parte de una investigación de posgrado (stricto sensu) realizada con estudiantes de $6^{\circ}$ y $7^{\circ}$ grado de una escuela privada en el municipio de Nova Iguaçu (RJ). Con el fin de identificar las posibilidades interdisciplinarias de trabajar con Educación Ambiental en las clases de campo, basadas en la enseñanza de las ciencias, realizamos una investigación acción, con un enfoque cualitativo. Los datos fueron recolectados durante las clases, antes y después de las clases de campo, a través de grabaciones de audio y producciones realizadas por

\footnotetext{
${ }^{1}$ Mestra em Práticas de Educação Básica pelo Colégio Pedro II (MPPEB) e graduada em Licenciatura plena em Ciências Biológicas pela UFRJ - Mestranda do curso de Ciências Ambientais e Florestais da UFRRJ - E-mail: andrademarianabio@gmail.com

${ }^{2}$ Doutora em Ecologia Social pelo Programa EICOS/UFRJ - Professora do Mestrado Profissional em Práticas de Educação Básica do Colégio Pedro II (MPPEB/CPII) - E-mail: alineviegas26@gmail.com ${ }^{3}$ Doutor em Física pelo Instituto de Física da UFRJ (IF-UFRJ) - Professor efetivo do Colégio Pedro II e do Mestrado profissional Práticas em Educação Básica (MPPEB - CPII) - E-mail: educapossoli@gmail.com
} 
los estudiantes. Estos datos se analizaron a la luz del análisis de contenido de Bardin. A través del análisis de los datos, se puede apreciar que la visita a los lugares de la clase de campo propició la movilización de conocimientos de diferentes áreas, encaminados a comprender la realidad socioambiental observada. Tal movilización contribuyó a la construcción de una concepción crítica de la Educación Ambiental.

Palabras clave: Educación ambiental. Clase de campo. Enseñanza de las ciências. Interdisciplinariedad.

\section{Introdução}

Um dos fatores que contribuiu para o surgimento da Educação Ambiental (EA) foram os movimentos sociais e, ao adentrar na pauta de debate mundial, a partir da realização de encontros e conferências, foram produzidos diversos documentos que enfatizavam a importância de a EA estar presente nas escolas, de maneira interdisciplinar. Esses documentos influenciaram a legislação brasileira, com a EA estando presente na Política Nacional de Meio Ambiente - Lei no 6.938/1981 (BRASIL, 1981), na Constituição Federal de 1988 (BRASIL, 1988), nos Parâmetros Curriculares Nacionais (BRASIL, 1998), a partir do tema transversal Meio Ambiente; na Política Nacional de Educação Ambiental - Lei no 9.795/1999 (BRASIL, 1999) e nas Diretrizes Curriculares Nacionais para a Educação Ambiental (BRASIL, 2012).

Porém, de acordo com Guimarães et al. (2009), na maioria das vezes a EA está presente nas escolas devido às iniciativas de alguns professores, pois apesar de institucionalizada não existe nenhuma imposição para que ela seja trabalhada como um conteúdo específico. Indo um pouco mais além na realidade escolar, Lima (2006) aponta que as dificuldades em se trabalhar a EA de forma interdisciplinar vão além da fragmentação dos conteúdos nos currículos escolares e/ou da falta de interesse dos professores, mas, também, são resultado da falta de encontros para se discutir o planejamento de projetos interdisciplinares e da formação dos professores em EA. Compreendemos, portanto, que a inserção da EA nos currículos escolares não é tarefa simples, principalmente em uma perspectiva interdisciplinar.

Entretanto, acreditamos ser importante trazer questões relacionadas à EA para o âmbito escolar, uma vez que a escola se constitui como um local propício para a formação do cidadão (LIOTTI, 2015), e entendemos que essa discussão não deve se restringir às disciplinas que tratam diretamente de temas ambientais, mas, sim, levar em conta o caráter interdisciplinar, que está na própria essência da EA (GUIMARÃES, 2015).

Pensando, então, em estratégias para se trabalhar a EA na escola, de maneira interdisciplinar, buscamos realizar aulas de campo, já que essas aulas permitem a observação da natureza e o estudo das relações entre os seres vivos, da relação do homem com o meio ambiente, em seus aspectos culturais, sociais, históricos e políticos. Além disso, a aula de campo pode contribuir para que o estudante conheça os problemas ambientais que o cercam, confrontando a teoria aprendida em sala de aula com a prática (VIVEIRO; DINIZ, 2009). Acreditamos, portanto, que o estudo do e no meio ambiente pode ser um eixo integrador entre as diferentes disciplinas, além de proporcionar uma visão integradora da realidade, contribuindo para a discussão de questões relacionadas à Educação Ambiental.

Nesse sentido, partindo do seguinte questionamento: as aulas de campo utilizadas no ensino de Ciências possibilitam a inserção da Educação Ambiental nos currículos escolares, em uma perspectiva interdisciplinar? Traçamos como um dos objetivos identificar possibilidades interdisciplinares de trabalhar a Educação Ambiental nas aulas de campo, a partir do ensino de Ciências. A pesquisa foi realizada com estudantes do $6^{\circ}$ e $7^{\circ}$ ano do Ensino Fundamental de uma escola privada, localizada na cidade de Nova Iguaçu (RJ). A aula de campo do $6^{\circ}$ ano aconteceu no rio Tatu Gamela, localizado próximo à escola, e a aula de campo do $7^{\circ}$ ano ocorreu na Reserva Biológica (Rebio) do Tinguá. Além das aulas de campo, efetuamos aulas de Ciências anteriores e posteriores, que foram utilizadas para a coleta dos dados apresentados ao longo do artigo. 


\title{
2 Referencial Teórico
}

Como citado de forma breve na introdução, os documentos de referência em EA orientam a sua inserção na escola de maneira interdisciplinar. A Carta de Belgrado, promulgada no Encontro Internacional sobre Educação Ambiental, realizado em 1975, na Iugoslávia, apresenta como uma de suas diretrizes básicas: "3. A Educação Ambiental deve conter uma abordagem interdisciplinar." (SÃO PAULO, 1994, p. 13). Da mesma forma, a Declaração de Tiblisi, documento redigido em Conferência realizada em 1977, apresenta como um dos seus princípios diretores para a EA: "Empregar um enfoque interdisciplinar, aproveitando o conteúdo específico de cada disciplina, para que se adquira uma perspectiva global e equilibrada" (SÃO PAULO, 1994, p. 31). A Segunda Conferência Mundial sobre a EA, que aconteceu em Moscou, em 1987, também reforça o caráter interdisciplinar da EA:

\begin{abstract}
- A EA resulta uma dimensão do conteúdo e da prática da educação orientadora para a resolução dos problemas concretos embasados pelo meio ambiente, graças a um enfoque interdisciplinar e a uma participação ativa e responsável de cada indivíduo e da coletividade.

[...] - Daqui se depreende outra de suas características fundamentais, a saber: a perspectiva interdisciplinar, em que se inscreve para tomar ciência da complexidade dos problemas ambientais e da multiplicidade dos fatores que se explicam. (GUIMARÃES, 2015, p. 45).
\end{abstract}

Em relação à legislação brasileira, o decreto 4281/02 que regulamenta a Lei no 9.795 que institui a Política Nacional de Educação Ambiental - orienta em seu artigo $5^{\circ}$ "I - a integração da educação ambiental às disciplinas de modo transversal, contínuo e permanente;" (BRASIL, 2002). Já o art. $8^{\circ}$ da Resolução 02/12, que estabelece as Diretrizes Curriculares Nacionais para a Educação Ambiental, orienta que:

\footnotetext{
A Educação Ambiental, respeitando a autonomia da dinâmica escolar e acadêmica, deve ser desenvolvida como uma prática educativa integrada e interdisciplinar, contínua e permanente em todas as fases, etapas, níveis e modalidades, não devendo, como regra, ser implantada como disciplina ou componente curricular específico. (BRASIL, 2012, p.3).
}

Apesar dessas orientações, o que se percebe, na prática, é uma grande dificuldade de implementação da EA no contexto escolar da forma como é orientada pelos documentos de referência e pela legislação. Guimarães et al. (2009) apontam que, muitas vezes, a EA vem sendo inserida nas escolas através de iniciativas espontâneas dos professores. Para os autores,

[...] apesar da EA estar institucionalizada com leis e políticas públicas próprias para o setor, de modo geral, não há nenhuma imposição para que um determinado professor, ou a EA esteja presente como um conteúdo específico na grade curricular, o que indica que ela está acontecendo nas escolas por iniciativa de alguns educadores. (GUIMARÃES et al., 2009, p. 50).

Para tentarmos compreender quais são os entraves para a potencialização da inserção de uma EA interdisciplinar no contexto escolar, discutimos, primeiro, sobre o conceito de interdisciplinaridade à luz do referencial teórico deste trabalho. É importante ressaltar que apesar da palavra interdisciplinaridade ser utilizada em diversos documentos oficiais e no cotidiano escolar, ela pode apresentar diversos significados revelando seu caráter polissêmico. Segundo o dicionário Houaiss da Língua Portuguesa, interdisciplinaridade é algo "que estabelece relações entre duas ou mais disciplinas ou ramos de conhecimento" ou "que é comum 
a duas ou mais disciplinas" (HOUAISS, 2015). Porém, ao falar de interdisciplinaridade, nesta pesquisa, buscamos ir além do conceito de integração de diversas disciplinas em torno de um tema comum.

Segundo Ivani Fazenda, pedagoga que estuda a interdisciplinaridade desde a década de 1970, e criadora do Grupo de Estudos e Pesquisa sobre Interdisciplinaridade na Educação (GEPI), "Interdisciplinaridade é uma nova atitude frente à questão do conhecimento, de abertura à compreensão de aspectos ocultos do ato de aprender e dos aparentemente expressos colocando-os em questão" (FAZENDA, 2011, p. 10).

Ao longo de suas pesquisas, Fazenda não conceitua o que é interdisciplinaridade, e expõe que "não existe um conceito único para ela, que cada enfoque depende basicamente da linha teórica de quem pretende delineá-la" (FAZENDA, 2007, p. 28), e também defende que, para refletir sobre a interdisciplinaridade, é necessário vivenciá-la na prática e observá-la.

De acordo com Cascino (1999), muitos educadores entendem que a interdisciplinaridade é o cruzamento entre conteúdos em comum de determinadas disciplinas, o que faz com que projetos ou atividades interdisciplinares acabem ocorrendo entre disciplinas que têm alguma afinidade. Dessa forma, são escolhidos temas-chave, utilizados como articuladores dessa integração. Porém, para o autor a ação interdisciplinar vai além da integração de disciplinas em torno de um tema comum, ela requer uma postura pesquisadora, de curiosidade em relação ao desconhecido, de reconstrução dos conteúdos disciplinares a partir da relação com o outro, com o diferente, modificando e também sendo modificado nesse processo. "Assim, não se trata de simples cruzamento de "coisas" parecidas; trata-se, bem ao contrário, de constituir diálogos fundados na diferença, abraçando concretamente a riqueza derivada da diversidade" (CASCINO, 1999, p. 69).

Cascino (1999, p. 73) ressalta que sempre se disse que a prática interdisciplinar é fundamental para o desenvolvimento da EA, e que essa afirmação tem fundamento no próprio histórico da Educação Ambiental. Além disso, o autor aponta que essa característica se constitui em um importante instrumento para a superação de práticas educativas tradicionais, e comenta que a superação dessas práticas requer uma fundamentação conceitual sólida, ao apresentar que "pesquisas recentes revelam que a construção de práticas interdisciplinares pressupõe a existência de campos disciplinares estruturados, com professores, coordenadores, monitores, etc., apresentando profunda formação em suas próprias disciplinas".

Nessa mesma obra, o autor também comenta que muitas atividades são desenvolvidas na escola sob o rótulo da EA e "que apontam para inúmeras leituras do que é educação, do que é ambiente, do que é consumo, do que é desequilíbrio, do que é preservação, etc." (CASCINO, 1999, p. 79). Para o autor, essa polissemia pode gerar divergências ideológicas que seriam ricas para a pluralização de leituras do real, mas que, muitas vezes, são utilizadas em batalhas por controle de conceitos, onde se procura a homogeneização de ideias, típico dos poderes conservadores. Segundo o autor, negar a ambiguidade, o diferente, vai na contramão do próprio movimento ambientalista.

Em sua tese de doutorado, Lima (2011) diz que o conceito de interdisciplina surgiu nos anos 1970, como uma crítica ao sistema capitalista, ao funcionamento da universidade e à falta de relevância social nos currículos escolares. Dessa forma, a interdisciplina surgiu como uma possibilidade de reunir teoria e prática e de superar a especialização excessiva.

Lima (2011) discute a interdisciplinaridade no contexto da Educação Ambiental, apresentando a visão de Ivani Fazenda, mas também de outros autores que se contrapõe à visão de Fazenda. Segundo a autora,

As abordagens de Follari, Casanova, Jantsch e Bianchetti, Etges e Frigotto se apresentam como alternativa teórico-metodológica à perspectiva fenomênica de Fazenda - que entende os sujeitos isolados de seus contextos de ação e a 
interdisciplinaridade como responsabilidade individual - também predominante no campo da EA (LIMA, 2011, p. 140).

Lima (2011, p. 137) expõe que existem dois paradigmas científicos para se discutir a interdisciplinaridade: a filosofia do sujeito e o marxismo dialético ${ }^{4}$ "No campo da filosofia do sujeito, a interdisciplinaridade evidencia a autonomia das ideias ou do sujeito pensante sobre os objetos". Esse paradigma apresenta uma visão a-histórica da produção do conhecimento e tem uma concepção de que o trabalho em parceria, ou seja, de que a interdisciplinaridade seria capaz de superar o problema da especialização das ciências.

Uma crítica da autora a esse paradigma está no fato de que, na perspectiva a-histórica, não importa o contexto onde está sendo produzido o conhecimento, desde que exista o trabalho em parceria essa produção já estaria satisfeita. Dessa forma, se abdica da ideia de que a produção do conhecimento depende das condições objetivas de cada contexto. Além disso, para a autora uma visão mais crítica em relação à interdisciplinaridade é importante para "retirar da interdisciplinaridade um caráter de utopia ou de um ato de vontade" (LIMA, 2011, p. 140).

Em relação ao materialismo dialético, Lima (2011) aponta que as questões sobre interdisciplinaridade são analisadas à luz da materialidade das relações capitalistas de produção da existência. A autora aponta que Frigotto (2004, apud LIMA, 2011) utiliza a dialética marxiana para compreender que a produção do conhecimento não é neutra, visto que as relações que ele tenta apreender também não o são. Nesse sentido, Frigotto (2008, p. 43) aponta que a questão da interdisciplinaridade se apresenta como necessidade, mas também como um problema. Para o autor, a necessidade de realização de um trabalho interdisciplinar "não decorre de uma arbitrariedade racional e abstrata. Decorre da própria forma do homem produzir-se enquanto ser social e enquanto sujeito e objeto do conhecimento social". Em relação aos entraves encontrados na realização de um trabalho interdisciplinar, o autor referido comenta que,

[...] a interdisciplinaridade se apresenta como problema pelos limites do sujeito que busca construir o conhecimento de uma determinada realidade e de outro pela complexidade desta realidade e seu caráter histórico. Todavia esta dificuldade é potenciada pela forma específica que os homens produzem a vida de forma cindida, alienada no interior da sociedade de classe (FRIGOTTO, 2008, p. 47).

Essas diferentes visões apresentadas por Lima (2011) são importantes para compreendermos a complexidade que envolve a questão da interdisciplinaridade e a dificuldade de se realizar um trabalho de EA nas escolas, atendendo a essa premissa interdisciplinar.

Com base nos apontamentos apresentados, entendemos que a realização de um trabalho interdisciplinar de EA nas escolas não é tarefa fácil, porém, acreditamos na sua importância. Por esse motivo, procuramos nos basear em pesquisas que apontam as contribuições das aulas de campo para o desenvolvimento de um trabalho de Educação Ambiental voltado para uma perspectiva interdisciplinar. Podemos citar o trabalho de Viveiro (2006), que buscou investigar como um grupo de professores inseria a aula de campo em sua atividade pedagógica. A autora destaca que a partir das aulas de campo "muitos conteúdos curriculares podem ser trabalhados e, sempre que possível, deve-se procurar envolver todas as componentes curriculares, explorando a visita de maneira interdisciplinar" (VIVEIRO, 2006, p. 38).

Reis (2016) realizou uma pesquisa com estudantes do segundo segmento do Ensino Fundamental que participaram de aulas de campo no município de Volta Redonda (RJ). A partir da análise dos dados, afirma que "chega-se a consideração de que a aula de campo pode constituir poderosa ferramenta de auxílio na tarefa de elaboração e constituição de uma proposta

${ }^{4}$ Neste texto, a utilização do termo marxismo dialético está apoiada na pesquisa de Lima (2011). 
de educação ambiental crítica e interdisciplinar" (REIS, 2016, p.87). Ainda sobre essa questão, em sua dissertação de mestrado Nascimento (2015) atesta as contribuições da aula de campo para o desenvolvimento de um trabalho interdisciplinar e para o ensino da EA crítica, a partir de uma pesquisa realizada com estudantes do $9^{\circ}$ ano que participaram de aulas de campo.

Julgamos ser importante pontuar que, ao nos referirmos à Educação Ambiental crítica, estamos tratando da EA pautada na perspectiva da Teoria Crítica, defendida, entre outros autores brasileiros, por Mauro Guimarães e Carlos Frederico Loureiro. Entendemos que essa vertente da EA tem por objetivo compreender a complexidade que envolve os problemas socioambientais, reconhecendo as dimensões históricas, políticas, sociais, econômicas e culturais que estão interconectadas a estes. Além disso, se caracteriza por reconhecer que as relações de poder da sociedade capitalista estão no âmago da crise socioambiental, e que por isso é necessária uma mudança radical nas bases que sustentam esse modelo de sociedade, o que pressupõe uma educação emancipatória, no sentido de permitir que o educando se reconheça como um agente social que é transformado, mas, também, capaz de transformar a história (LOUREIRO, 2004; GUIMARÃES, 2016).

Nesse sentido, de acordo com essa vertente da EA, é importante que o ambiente seja compreendido como uma unidade, de forma inteira, não fragmentada, e uma abordagem interdisciplinar das questões socioambientais pode contribuir para essa compreensão mais ampla (GUIMARÃES, 2015). Nessa perspectiva, as aulas de campo se apresentam como uma metodologia eficaz para o estudo integral do ambiente, pois permitem que o estudante interaja com elementos do seu meio, do dia a dia, e como a realidade não se apresenta fragmentada, torna-se mais fácil, até mesmo espontâneo, o estudo interdisciplinar de questões ambientais.

\section{Procedimentos Metodológicos}

Este trabalho é parte de uma pesquisa de pós-graduação (stricto sensu) que foi autorizada pelo Comitê de Ética em Pesquisa (CEP). A pesquisa teve como objetivo geral analisar como as aulas de campo, realizadas a partir das aulas de Ciências, permitiam um trabalho interdisciplinar voltado para a inserção da EA nos currículos escolares. Descreve, como um dos objetivos específicos, identificar possibilidades interdisciplinares de trabalhar a Educação Ambiental nas aulas de campo, a partir do ensino de Ciências.

Para a realização deste trabalho, optamos pelo método da pesquisa-ação, que segundo Thiollent (1986, p. 14) corresponde a

[...] um tipo de pesquisa com base empírica que é concebida e realizada em estreita associação com uma ação ou com a resolução de um problema coletivo e no qual os pesquisadores e participantes representativos da situação ou do problema estão envolvidos de modo cooperativo ou participativo.

A escolha por esse tipo de pesquisa se deu pela forma como a mesma se desenvolveu: em sala de aula, onde tanto os alunos, quanto a professora/pesquisadora, estiveram envolvidos com o objeto de pesquisa, refletindo, discutindo e construindo conhecimentos sobre questões como: Educação Ambiental; aulas de campo; ensino de Ciências e interdisciplinaridade. Além disso, é importante ressaltar que utilizamos a abordagem qualitativa já que, segundo Ivenicki e Canen (2016), as pesquisas qualitativas apresentam, como uma de suas características, a rejeição à neutralidade do pesquisador, devido à dificuldade de separar o pesquisador do objeto de pesquisa, que, nesse caso, é a própria realidade. Outro aspecto é a coleta de dados descritivos, o que acaba fazendo com que a análise tenha uma ênfase na interpretação e não em dados observáveis, que podem ser medidos estatisticamente. 
A coleta de dados ocorreu em uma escola privada da cidade de Nova Iguaçu (RJ). Os sujeitos da pesquisa foram os quinze alunos do $6^{\circ}$ ano e os dez alunos do $7^{\circ}$ ano que participaram das aulas de campo, assim como das aulas anteriores e posteriores.

A aula de campo do $6^{\circ}$ ano ocorreu no rio Tatu Gamela, que se localiza próximo à escola e, por isso, muitos estudantes passam por ele no caminho para as aulas, além de alguns alunos viverem nas suas proximidades. O rio se encontra bastante poluído, com diversas canalizações que despejam esgoto sem tratamento em suas águas. Além da aula de campo, realizamos uma aula anterior e duas aulas posteriores à aula de campo, onde buscamos trabalhar o conteúdo de Ciências relacionado ao saneamento básico, por acreditarmos na importância da reflexão crítica desse tema.

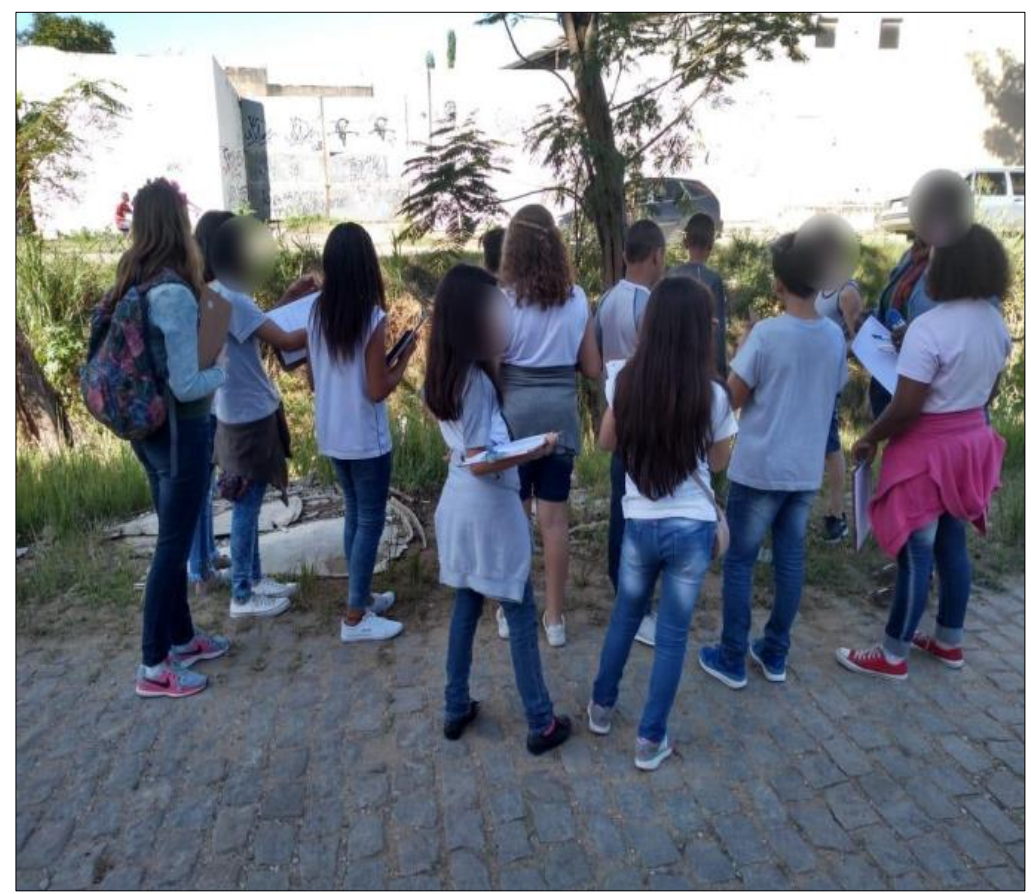

Figura 1 - Alunos do $6^{\circ}$ ano durante a aula de campo no rio Tatu Gamela Fonte: a autora, 2020

$\mathrm{Na}$ aula anterior à aula de campo no rio Tatu Gamela, abordamos questões relacionadas aos aspectos históricos e geográficos da cidade de Nova Iguaçu, com foco nos rios existentes próximos das casas dos estudantes. Além disso, discutimos sobre a importância dos rios e a diferença entre um rio e um valão. Na segunda aula, que aconteceu após a aula de campo no rio Tatu Gamela, realizamos um debate com o objetivo de compreender qual foi a percepção dos estudantes a respeito da aula de campo, abordando as opiniões dos alunos sobre as entrevistas que foram realizadas com moradores locais e questão da importância de conhecermos o local onde vivemos. Na terceira aula, retomamos a discussão iniciada na aula anterior sobre as causas e consequências da degradação do rio Tatu Gamela, os responsáveis por essa situação e o que poderia ser feito para melhorar a condição do rio.

A aula de campo do $7^{\circ}$ ano aconteceu na ReBio do Tinguá, uma Unidade de Conservação que abrange os municípios de Nova Iguaçu, Petrópolis, Duque de Caxias e Miguel Pereira, e apresenta um fragmento da Mata Atlântica preservada (SANTOS, 2014). Nessa turma, realizamos uma aula anterior e três aulas posteriores à aula de campo e buscamos abordar o conteúdo sobre biomas, com enfoque para o bioma Mata Atlântica, pelo fato de os estudantes estarem inseridos nesse bioma e assim ser possível levantar discussões relacionadas à EA com base em uma realidade que é próxima dos alunos. 


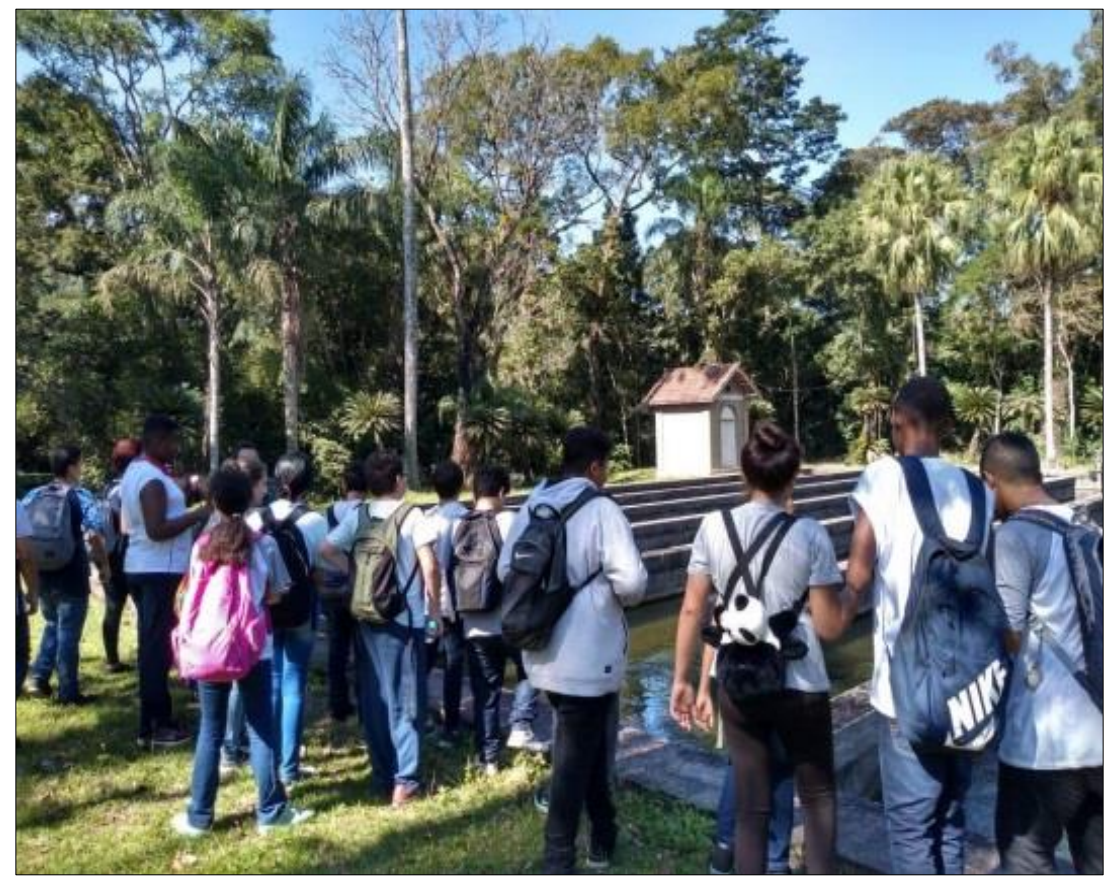

Figura 2 - Alunos durante a aula de campo na ReBio do Tinguá

Fonte: a autora, 2020

Na primeira aula, anterior à aula de campo, discutimos com os alunos sobre as características do bioma Mata Atlântica e as causas e consequências de sua degradação. Também, apresentamos para os estudantes um pouco da história da ReBio do Tinguá e falamos sobre as espécies de animais e plantas encontradas ali. A segunda aula, que ocorreu após a aula de campo, foi realizada no formato de roda de conversa onde os estudantes puderam expressar suas opiniões e sentimentos em relação à aula de campo da qual tinham participado. A terceira aula teve como objetivo apresentar e discutir, em conjunto com os estudantes, um pouco sobre a história e geografia da ReBio do Tinguá. Essa aula surgiu a partir de uma necessidade apontada pelos próprios alunos, pois durante a aula de campo os estudantes conheceram muitos aspectos relacionados à fauna e à flora encontradas na Reserva, porém, surgiram algumas dúvidas, relacionadas principalmente aos aspectos históricos observados na Reserva.

Portanto, em uma aula posterior à aula de campo, os estudantes foram até o laboratório de informática pesquisar sobre os aspectos históricos e geográficos da ReBio, mas, infelizmente, não encontraram muitas informações sobre o local, principalmente com uma leitura acessível. Por esse motivo nós realizamos essa terceira aula, onde apresentamos aos estudantes um pouco sobre a história e geografia da região de Tinguá e da ReBio do Tinguá. Com base nessa apresentação, na pesquisa que já havia sido realizada pelos próprios alunos e no que eles observaram na aula de campo, realizamos uma discussão sobre os aspectos históricos e geográficos da ReBio do Tinguá. Na quarta aula, os alunos realizaram uma atividade sobre o que entendiam do termo meio ambiente e a partir de suas respostas iniciamos um debate sobre a relação ser humano-natureza, degradação ambiental e os responsáveis por essa degradação, sempre fazendo um paralelo com a aula de campo.

Os dados da pesquisa foram coletados nessas aulas anteriores e posteriores às aulas de campo, realizadas com as turmas do $6^{\circ}$ e $7^{\circ}$ ano, por meio da gravação em áudio, além de coletarmos, também, as produções dos estudantes a respeito das atividades propostas. As gravações em áudios foram transcritas, tratadas e analisadas por meio do método da Análise de Conteúdo de Bardin (2016).

Para a realização da Análise de Conteúdo, Bardin (2016) aponta que são necessárias três etapas: a pré-análise; a exploração do material; e o tratamento dos resultados, inferência e 
interpretação. Na etapa da pré-análise deve ser feita a escolha dos documentos que serão analisados, a formulação das hipóteses e dos objetivos e a elaboração dos indicadores, que irão fundamentar a interpretação final. A segunda etapa corresponde à exploração do material e, segundo Bardin (2016, p. 101), "a fase de análise propriamente dita não é mais do que a administração sistemática das decisões tomadas. [...] Esta fase, longa e fastidiosa, consiste essencialmente de operações de codificação, desconto ou enumeração, em função de regras previamente formuladas.”. A terceira etapa da Análise de Conteúdo consiste no tratamento dos resultados obtidos e na interpretação desses resultados.

A partir do momento que observamos, por meio da leitura flutuante dos dados, a presença da concepção de EA conservadora e construção de uma concepção de EA crítica, procuramos encontrar os elementos que caracterizavam cada uma dessas concepções, para que pudessem ser os indicadores que iriam auxiliar na classificação dos conteúdos de fala dos estudantes em cada uma dessas categorias. Para tal, utilizamos como referência alguns apontamentos de Loureiro (2006) e Guimarães (2007), já citados anteriormente, e também apontamentos de Layrargues e Lima (2011) e Layrargues (2012) referentes a essas duas grandes vertentes da Educação Ambiental. Em relação à concepção de EA conservadora, sentimos a necessidade de dividi-la em subcategorias e, para isso, nos baseamos, além dos autores citados anteriormente, nos trabalhos de Tamaio (2000), Sauvé (2005) e Oliveira (2012). A partir desse processo, elaboramos os Quadros 1 e 2, exibidos a seguir, que apresentam os indicadores de cada uma das categorias de concepção de EA e que serviram de base para a classificação e posterior análise dos conteúdos de fala dos estudantes.

\begin{tabular}{|c|c|c|c|}
\hline Visão naturalista & Visão recursista & $\begin{array}{l}\text { Visão individualista/ } \\
\text { comportamentalista }\end{array}$ & Sustentabilidade $^{5}$ \\
\hline $\begin{array}{l}\text { Mobilização de sentimentos } \\
\text { para com a natureza e } \\
\text { presença de uma visão } \\
\text { romântica do meio ambiente, } \\
\text { que é visto como um local } \\
\text { limpo, tranquilo e com } \\
\text { paisagens e animais exóticos } \\
\text { e exuberantes. }\end{array}$ & \multirow[t]{3}{*}{$\begin{array}{l}\text { Natureza vista } \\
\text { como fonte de } \\
\text { recurso para o } \\
\text { ser humano. }\end{array}$} & $\begin{array}{l}\text { Ênfase na conscientização } \\
\text { das pessoas, para que } \\
\text { ocorram mudanças de } \\
\text { comportamento individual } \\
\text { para a resolução dos } \\
\text { problemas ambientais. }\end{array}$ & $\begin{array}{l}\text { Visão pautada na ideia de } \\
\text { sustentabilidade, onde a } \\
\text { crise ambiental pode ser } \\
\text { resolvida se os recursos } \\
\text { naturais forem utilizados de } \\
\text { maneira consciente. }\end{array}$ \\
\hline $\begin{array}{l}\text { Visão preservacionista, com } \\
\text { ênfase na proteção integral } \\
\text { da natureza, que deve ficar } \\
\text { livre da presença humana. }\end{array}$ & & $\begin{array}{l}\text { Visão do ser humano como } \\
\text { um ser genérico, visto como } \\
\text { vítima e causador da crise } \\
\text { ambiental. }\end{array}$ & \multirow[t]{2}{*}{$\begin{array}{l}\text { Ênfase na ideia de que } \\
\text { todos devem se unir para } \\
\text { resolver os problemas } \\
\text { ambientais. }\end{array}$} \\
\hline $\begin{array}{l}\text { Visão ecologizada do meio } \\
\text { ambiente e dos problemas } \\
\text { ambientais, com foco para os } \\
\text { aspectos biológicos } \\
\text { científicos. }\end{array}$ & & $\begin{array}{l}\text { Ênfase em problemas } \\
\text { ambientais genéricos, como a } \\
\text { questão do lixo, economia da } \\
\text { água, preservação de } \\
\text { espécies ameaçadas de } \\
\text { extinção e desmatamento. }\end{array}$ & \\
\hline
\end{tabular}

Quadro 1 - Indicadores referentes às subcategorias da concepção conservadora de EA

Fonte: a autora, 2020

\footnotetext{
${ }^{5}$ Layrargues e Lima (2011) apresentam três macrotendências que comportam as tendências político-pedagógicas de EA no Brasil: a vertente conservacionista, a crítica e a pragmática. Esta última compreende a ideia de desenvolvimento sustentável e a noção de sustentabilidade, porém, apesar de se apresentar como uma vertente mais atual de EA, Layrargues (2012) ressalta que a macrotendência pragmática constitui uma derivação histórica da vertente conservacionista. Por esse motivo, e por nos basearmos nas ideias de Loureiro e Guimarães, que apontam para duas concepções predominantes de EA: a crítica e a conservadora, optamos por incluir a categoria Sustentabilidade dentro da concepção de EA conservadora.
} 


\section{CONSTRUÇÃO DA CONCEPÇÃO CRÍTICA DA EDUCAÇÃO AMBIENTAL}

Enxerga outras dimensões, além do aspecto natural, em uma aula de campo e reconhece a importância de se aprender sobre diferentes aspectos do meio ambiente para compreender a sua complexidade.

Percebe como o conhecimento histórico contribui para a compreensão da realidade de uma forma mais abrangente.

Reconhece as relações de poder e exploração existentes em nossa sociedade e que implicam na degradação do meio ambiente.

Compreende que a mobilização social é um importante instrumento para mudar as relações de dominação estabelecidas em nossa sociedade.

Entende que mudanças pontuais e individuais não são suficientes para resolver a atual crise socioambiental.

Compreende as diversas causas dos problemas socioambientais, assim como reconhece quem são os responsáveis pela resolução desses problemas.

Realiza uma reflexão sobre problemas socioambientais globais a partir da constatação de problemas socioambientais do seu cotidiano.

Quadro 2 - Indicadores referentes à construção da concepção crítica de EA

Fonte: a autora, 2020

\section{Resultados e Discussões}

Partindo da premissa de que a Educação Ambiental é, em essência, interdisciplinar (GUIMARÃES, 2015), pretendemos demonstrar de que forma conseguimos alcançar a interdisciplinaridade ao longo das aulas de Ciências realizadas com as turmas do $6^{\circ}$ e $7^{\circ}$ ano do Ensino Fundamental. É importante mencionar que, como exposto anteriormente, os conteúdos de fala dos estudantes foram categorizados de acordo com as concepções de EA que emergiram ao longo da leitura flutuante dos dados (Quadros 1 e 2). A partir dessa categorização, selecionamos os conteúdos de fala que se aproximavam dos indicadores presentes no Quadro 2 , principalmente aqueles onde os estudantes demonstravam mobilizar conhecimentos de outras áreas para a compreensão da problemática socioambiental apresentada e com base nesses conteúdos tecemos a análise apresentada a seguir.

Por meio do material selecionado para análise, foi possível observar que a aula de campo realizada na ReBio do Tinguá com a turma do $7^{\circ}$ ano contribuiu para que os estudantes percebessem diversos elementos relacionados ao conteúdo de Ciências e, além desses aspectos biológicos e científicos, os alunos puderam conhecer outras dimensões presentes naquele ambiente, mobilizando conhecimentos de outras áreas, como pode ser observado no conteúdo de fala do aluno 1:

Aluno 1: eu achei muito interessante, porque além da gente aprender sobre diversas espécies de plantas, diversas espécies de animais, o que são espécies exóticas e endêmicas e o perigo disso, a gente ainda viu aquela estrada histórica lá daquele período colonial, como aqueles escravos colocaram aquelas pedras para que eles pudessem passar, que era o caminho do ouro (ANDRADE, 2020, p. 123).

Desse modo, por meio do conteúdo de fala dos estudantes foi possível observar que a aula de campo acabou despertando o interesse dos mesmos em investigar um pouco mais sobre a história e a geografia da região, acarretando na realização de uma aula para discussão desses aspectos. Como salientam Chapani e Cavassan (1997, p. 32), "No estudo do meio, o professor de Ciências é obrigado a trabalhar de forma interdisciplinar e não linear. Talvez este seja um bom aprendizado para o professor, mostrando alternativas de se trabalhar conteúdos de uma forma mais global e menos departamentalizada.". De fato, a partir do interesse demonstrado 
pelos alunos se fez necessário estabelecer conexões com conhecimentos de outras áreas, o que nos levou a estabelecer uma prática interdisciplinar.

Percebemos, também, que a partir da abordagem dos aspectos históricos e geográficos da ReBio do Tinguá, em conjunto com o conteúdo de Ciências sobre os biomas, os estudantes compreenderam, de maneira mais abrangente, as diferentes dimensões socioambientais presentes na ReBio. Esse fato contribuiu para a discussão de questões relacionadas à EA voltadas para uma perspectiva mais crítica (Quadro 2), pois segundo Loureiro (2006, p. 33), umas das características indissociáveis da EA emancipatória é a "preocupação concreta em estimular o debate e o diálogo entre as ciências, redefinindo objetos de estudo e saberes;". Podemos observar as questões apontadas acima na fala da Aluna 6: "sem a contribuição da história, eu não saberia como ela se formou..." (A aluna estava se referindo à criação da ReBio do Tinguá). Também, na fala do Aluno 1:

\begin{abstract}
Aluno 1: há muito tempo lá tinha um local que eles tipo assim, a população vivia sem água. Já existia lá um parque né, que o Dom Pedro ficava estudando e tal, só que quando foi ficando mais lá para frente, lá para 1900, tinha um local que era planta e tal só que as pessoas estavam desmatando... esses aí, grandes empresas, investidores e tal. Aí a população teve uma hora que começou a se revoltar com isso, eles começaram a fazer tipo que abaixo-assinados, aí levaram isso para o governo, para prefeitura, para tudo quanto é lugar, fazendo um pedido para que criassem uma reserva, para proteger aquela área ali, que ainda estava restando pela região e como era uma coisa realmente impactante eles acabaram concordando em criar uma, que é a REBIO, reserva biológica (ANDRADE, 2020, p. 126).
\end{abstract}

Nesse sentido, assim como apontam Viveiro e Diniz (2009), percebemos que, como a aula de campo possibilita que os estudantes estejam em contato direto com o meio ambiente, ela pode contribuir para a mobilização de diversos saberes voltados para a percepção de diferentes elementos presentes no local em questão, indo além da visão dos aspectos meramente biológicos, além de poder auxiliar, também, na compreensão de problemas socioambientais que se manifestam explícita ou implicitamente, podendo desencadear discussões relacionadas à EA.

Nas aulas realizadas com a turma do $6^{\circ}$ ano observamos um caminho um pouco diferente, com a mobilização de conhecimentos de outras áreas se fazendo presentes antes mesmo da aula de campo. Podemos entender que esse movimento ocorreu por alguns motivos, como o fato de partirmos da análise de um problema socioambiental, que era a degradação do rio Tatu Gamela e, nesse caso, como aponta Loureiro (2008), é importante lembrar que toda problemática ambiental é complexa e interdisciplinar. Portanto, foi necessário apresentar para os estudantes alguns aspectos geográficos e históricos da região onde se localiza o rio, desde a aula anterior à aula de campo. Além disso, alguns estudantes trouxeram para a aula conhecimentos sobre o rio Tatu Gamela partindo de suas próprias vivências, por morarem próximos ao rio, como mostra o conteúdo de fala do Aluno 6: "nesse rio que a gente vai, tem o rio e várias casas na beira. Nessas casas tem um cano que já cai dentro do rio, aí tudo que eles usam dentro de casa já cai dentro do rio" (ANDRADE, 2020, p. 127).

Ainda assim, a aula de campo contribuiu para que os estudantes observassem de perto as diferentes causas da degradação do rio Tatu Gamela e conhecessem um pouco mais sobre a história desse rio, a partir das entrevistas que foram realizadas com antigos moradores do bairro. Essa atividade acarretou em um olhar diferenciado em relação ao rio, que era considerado um valão por muitos, até então, ou que nem era conhecido por alguns alunos que viviam perto dele, como mostram os conteúdos de fala sobre o que os estudantes acharam da aula de campo. "Aluna 12: diferente, porque eu não sabia que aquele rio era perto da minha casa". "Aluna 3: eu achei muito, muito legal e eu achei bem interessante porque descobrimos coisas que não sabíamos com as entrevistas". "Aluna 1: eu gostei de saber o porquê do nome, por causa dos 
tatuzinhos, dos tatus que moravam perto da nascente dele, mas depois os idiotas mataram eles...". "Aluno 6: que a gente aprendeu coisas que nem na internet dava para pesquisar" (ANDRADE, 2020, p. 128).

Dessa maneira, observamos que, além da aula de campo contribuir com a mobilização de conhecimentos de outras áreas, como a história e a geografia, ela também permitiu que os estudantes tivessem contato com o conhecimento popular, a partir das entrevistas realizadas com os moradores do bairro sobre o rio Tatu Gamela, que contaram um pouco sobre as memórias que tinham do rio, contribuindo para que os estudantes conhecessem um pouco mais sobre as causas e consequências da sua degradação e tivessem uma nova visão sobre o rio (Quadro 2). Essa situação se aproxima do que apontam Viveiro e Diniz (2009, p. 6), ao estabelecer que "conhecimentos de todas as áreas podem ser acionados para a compreensão e a discussão sobre o entorno ambiental". Esse fato também pode ser observado na produção textual de uma aluna, realizada a partir de uma questão da prova de Português, como mostra a Figura 3.

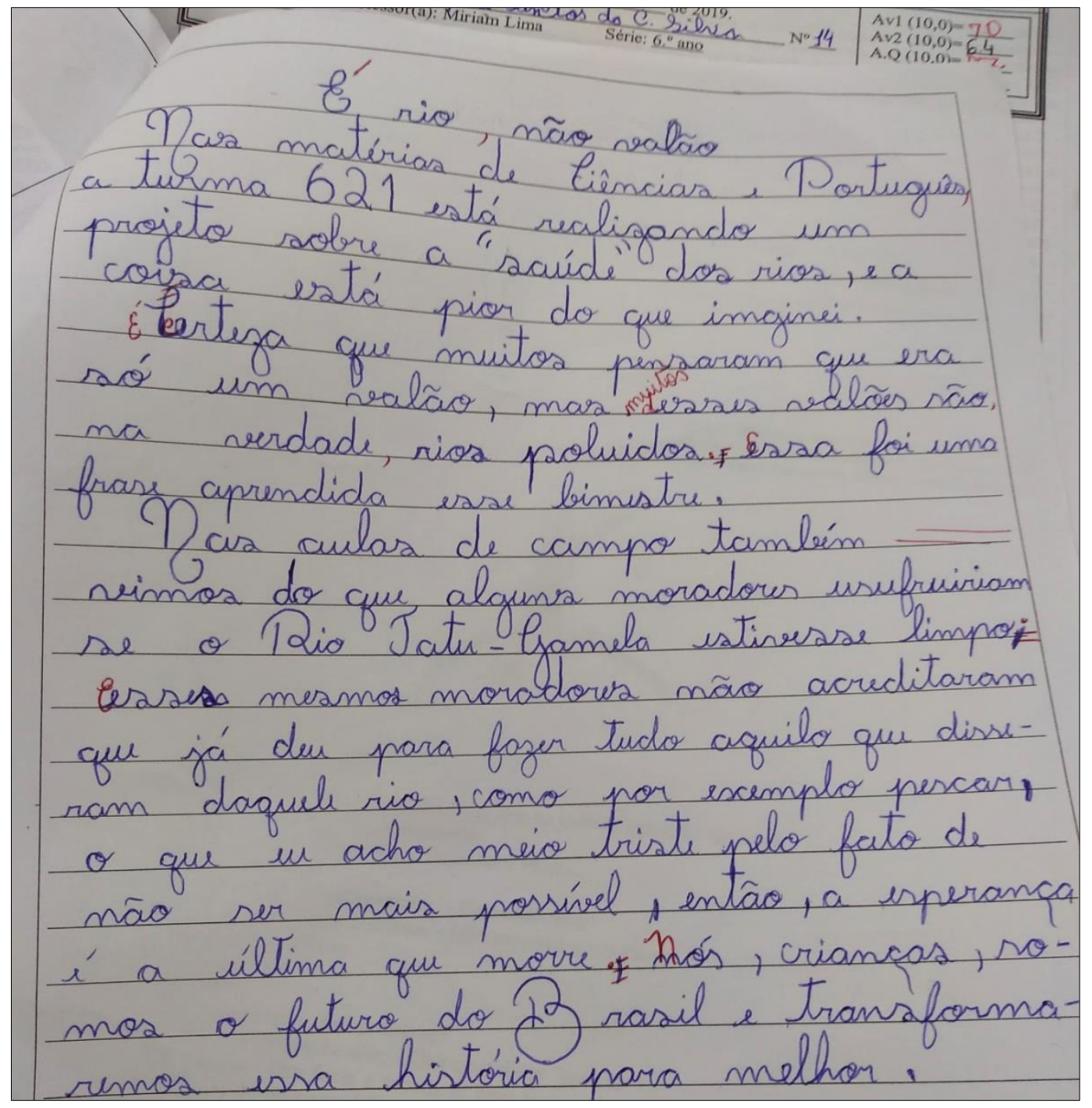

Figura 3 - Produção textual da aluna 2 sobre a aula de campo no rio Tatu Gamela Fonte: a autora, 2020

Neste momento, é importante destacar que a aula de campo realizada com a turma do $6^{\circ}$ ano no rio Tatu Gamela ocorreu em parceria com a professora de Português, que estava 
desenvolvendo um projeto sobre a água no âmbito da sua disciplina. Porém, apesar de termos realizado a aula de campo em conjunto, não foi possível efetuarmos o planejamento dessa aula de uma maneira integrada, devido, principalmente, à falta de tempo para nos encontrarmos e discutirmos sobre nossos objetivos em relação à aula de campo. Assim, como indica Lima (2011), percebemos que a realização de um trabalho interdisciplinar não depende somente da vontade do professor em ter uma atitude interdisciplinar, já que na realidade da escola existem diversos entraves que dificultam a realização desse trabalho. Ainda assim, acreditamos que os conhecimentos das disciplinas envolvidas no projeto, assim como a mobilização dos conhecimentos históricos, geográficos e também do conhecimento popular, contribuíram para que os estudantes pudessem compreender, de forma mais abrangente, a realidade socioambiental daquele local, como pode ser observado a partir dos conteúdos de fala e dos registros dos estudantes que foram apresentados ao longo desta seção de análise.

A partir da análise dos dados das aulas realizadas com as turmas do $6^{\circ}$ e $7^{\circ}$ ano observamos que, ao mesmo tempo em que aula de campo suscitou a mobilização de conhecimentos de diversas áreas, a percepção desses conhecimentos por parte dos alunos possibilitou uma compreensão mais ampla do ambiente visitado. Essas observações também estão de acordo com a pesquisa de Nascimento (2015). Por sua vez, Nascimento e Sgarbi (2015, p. 98) salientam que "Todo o trabalho desenvolvido com os alunos, envolvendo os momentos antes, durante e após as aulas de campo, envolveram os diferentes aspectos formadores do ambiente, incentivando o aluno no desenvolvimento de uma visão integradora do meio". Vejamos a Figura 4.

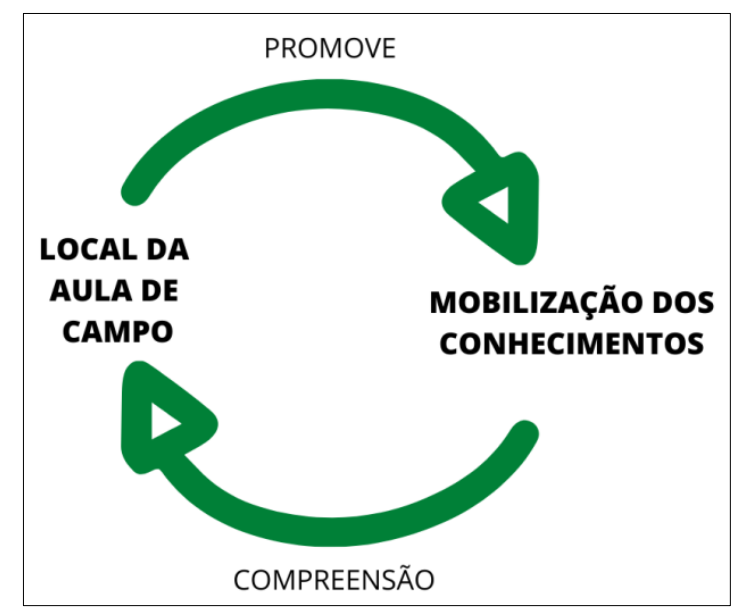

Figura 4 - Relação entre a aula de campo e a interdisciplinaridade Fonte: a autora, 2020

Nesse sentido, acreditamos que o enfoque interdisciplinar que foi dado aos aspectos observados durante a aula de campo permitiu que os estudantes percebessem as dimensões histórica, geográfica, biológica, afetiva, entre outras, presentes no local visitado, contribuindo para o debate de questões relacionadas à EA voltadas para uma perspectiva crítica, na medida em que desvelou alguns aspectos e relações envolvidas naquela realidade socioambiental observada (Quadro 2). Assim, entendemos que a aula de campo foi uma metodologia importante para suscitar a realização de um trabalho interdisciplinar. Como aponta Miranda (2008, p. 118), "A interdisciplinaridade se sustenta na base da leitura da realidade tal como ela é, assumindo suas nuances e singularidades, bem como a diversidade presente.". Compreendemos, portanto, que a aula de campo permitiu que os alunos estivessem em contato com essa realidade.

Por meio da discussão apresentada anteriormente, percebemos que as possibilidades interdisciplinares para trabalhar a EA tiveram como motor as próprias aulas de campo. No caso 
do $7^{\circ}$ ano, a aula de campo ocorreu no âmbito apenas da disciplina de Ciências, mas foi capaz de mobilizar conhecimentos históricos e geográficos, que foram abordados de maneira mais detalhada em uma aula posterior, a pedido dos alunos, e contribuíram para que os estudantes conhecessem, de maneira mais ampla, a história da ReBio do Tinguá. Já no $6^{\circ}$ ano, a aula de campo ocorreu em conjunto com a professora de Português, porém, como exposto anteriormente, não foi possível planejarmos essa aula de forma integrada, e as aulas anteriores e posteriores à aula de campo no rio Tatu Gamela ocorreram somente no âmbito da disciplina de Ciências. Assim como no $7^{\circ}$ ano, os conhecimentos de outras áreas (história, geografia, memórias da população local), foram utilizados para uma compreensão mais abrangente do local visitado e estimularam discussões de questões relacionadas à EA voltada para uma perspectiva crítica. Dessa forma, entendemos que o trabalho interdisciplinar realizado transcorreu segundo a visão de Loureiro (2006, p. 76), onde:

A interdisciplinaridade, nesse sentido e enquanto pressuposto da Educação Ambiental, não é um princípio epistemológico para legitimar determinados saberes e relações de poder hierarquizadas entre ciências, nem um método único para a articulação de objetos de conhecimentos, capaz de produzir uma "metaciência". É uma prática intersubjetiva que associa conhecimentos científicos e relaciona o racional com o intuitivo, o cognitivo com o sensorial, buscando a construção de objetos de conhecimentos que se abram para novas concepções e compreensões do mundo (natural estrito senso e histórico) e para a constituição do sujeito integral.

Apesar do que foi apresentado, sabemos que o trabalho interdisciplinar que buscamos realizar não foi capaz de fazer com que os estudantes tivessem uma compreensão total daquela realidade socioambiental observada, pois como aponta Frigotto (2008, p. 47), a interdisciplinaridade possui como entraves os "limites do sujeito que busca construir o conhecimento de uma determinada realidade e [...] a complexidade desta realidade e seu caráter histórico. Todavia esta dificuldade é potenciada pela forma específica que os homens produzem a vida de forma cindida [...]". Nesse sentido,

[...] mesmo que se atinja um elevado nível de capacitação crítica nenhum sujeito individual dá conta de exaurir determinada problemática. Este esforço é sempre acumulativo e social. Já, por este ângulo percebemos que o conhecimento humano sempre será relativo, parcial, incompleto. Daí a relevância de se buscar esclarecer, revelar, expor não toda a realidade de um fato mas sim as suas determinações e mediações fundamentais (FRIGOTTO, 2008, p. 48).

Porém, entendemos que o trabalho interdisciplinar que procuramos realizar foi importante na medida em que possibilitou aos estudantes enxergarem, não a realidade em sua totalidade, mas as diferentes dimensões presentes no local visitado, contribuindo para que os alunos pudessem estabelecer relações entre essas dimensões e compreendessem melhor a complexidade da situação socioambiental em questão, pois como indica Frigotto (2008, p. 48) a necessidade do trabalho interdisciplinar está na

[...] simples razão de que a parte que isolamos ou arrancamos 'do contexto originário do real' para poder ser explicada efetivamente, isto é, revelar no plano do pensamento e do conhecimento as determinações que assim a constituem, enquanto parte tem que ser explicitada na integridade das características e qualidades da totalidade.

Com base nos dados expostos, entendemos que a aula de campo, por possibilitar o contato direto com o ambiente, foi capaz de promover a mobilização de diversos conhecimentos voltados para uma compreensão mais ampla do local visitado e que o trabalho interdisciplinar, que teve como motor a própria apreensão da realidade socioambiental observada, se mostrou 
fundamental para a construção de uma concepção crítica de EA por parte dos estudantes (Figura 5). Essa afirmação vai ao encontro dos resultados obtidos na pesquisa de Nascimento (2015, p. 135), onde a autora aponta que

[...] As aulas de campo podem contribuir para o desenvolvimento de uma educação ambiental crítica à medida que promovem um ensino mais contextualizado, dinâmico e ativo por parte do discente, favorecem a interação e mediação entre sujeitos e sujeito-objeto, favorecem o trabalho de temas socioambientais, bem como da interdisciplinaridade, e desenvolvem os aspectos sensoriais e afetivos, além dos cognitivos, incentivando a pesquisa e a investigação.

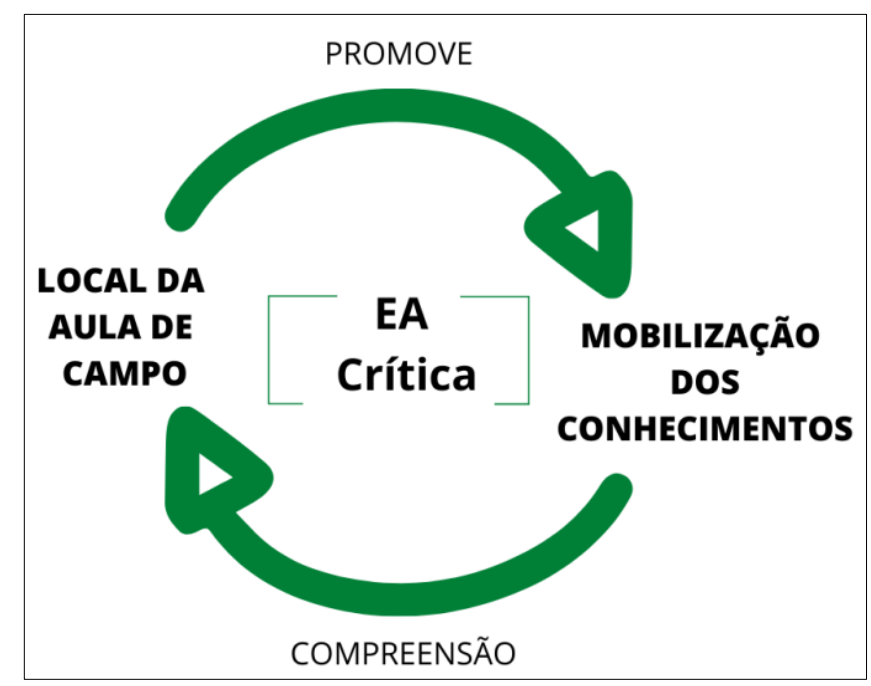

Figura 5 - Relação entre a aula de campo, a interdisciplinaridade e a EA crítica Fonte: a autora, 2020

\section{Considerações Finais}

Através dos resultados e discussões apresentados anteriormente, acreditamos que foi possível identificar possibilidades interdisciplinares de se trabalhar a Educação Ambiental em aulas de campo, a partir do ensino de Ciências. É possível dizer que a realização de um trabalho interdisciplinar se colocou como uma necessidade, uma vez que a própria aula de campo e as questões relacionadas à EA instigaram nos estudantes a vontade de entender sobre conhecimentos de outras áreas.

No entanto, é importante pontuar as dificuldades que encontramos para realizar as aulas de campo em conjunto com professores de outras disciplinas, como por exemplo, o horário disponível que os professores precisariam ter para acompanhar as turmas durante as aulas de campo e o tempo disponível para momentos de encontro a fim de planejar essas aulas em conjunto. Mesmo que a aula de campo no rio Tatu Gamela tenha ocorrido junto com a professora de Português, não foi possível pensar e planejar essa aula em conjunto, assim como as aulas anteriores e posteriores, o que impossibilitou a realização de atividades integradas entre as duas disciplinas.

Apesar dessas dificuldades, observamos que as aulas de campo na ReBio do Tinguá e no rio Tatu Gamela contribuíram para a mobilização de conhecimentos de outras áreas, voltados para uma percepção mais ampla dos locais visitados. Na turma do $7^{\circ}$ ano percebemos que a aula de campo motivou os estudantes a pesquisarem mais sobre os aspectos históricos e geográficos relacionados à ReBio do Tinguá. Já na turma do $6^{\circ}$ ano, observamos a mobilização de conhecimentos de outras áreas antes mesmo da visita ao rio Tatu Gamela, inclusive com a 
presença de conteúdos de fala dos estudantes demonstrando seus próprios conhecimentos em relação ao rio.

Dessa forma, foi possível realizarmos atividades e discussões que abordassem questões relacionadas à EA, não apenas voltadas para os aspectos biológicos observados nos locais das aulas de campo, mas que compreendessem, também, as diferentes dimensões - histórica, social, ambiental, política, etc. - presentes naqueles ambientes, o que pode ter auxiliado na construção de uma concepção crítica de EA (Quadro 2), voltada para uma compreensão mais ampla da realidade socioambiental observada.

\section{Referências}

BARDIN, L. Análise de conteúdo. São Paulo: Edições 70, 2016.

BRASIL. Lei n. 6.938, de 31 de agosto de 1981. Dispõe sobre a Política Nacional do Meio Ambiente, seus fins e mecanismos de formulação e aplicação, e dá outras providências. Brasília, 1981. Disponível em: http://www.planalto.gov.br/ccivil_03/leis/16938.htm. Acesso em: 07 mar. 2019.

BRASIL. Constituição da República Federativa do Brasil de 1988. Brasília, 1988. Disponível em: http://www.planalto.gov.br/ccivil_03/constituicao/constituicaocompilado.htm. Acesso em: 06 mar. 2019.

BRASIL. Secretaria de Educação Fundamental. Parâmetros Curriculares Nacionais: Ciências Naturais. Brasília: MEC/SEF, 1998. Disponível em: http://portal.mec.gov.br/seb/arquivos/pdf/ciencias.pdf. Acesso em: 06 mar. 2019.

BRASIL. Lei n. 9.795, de 27 de abril de 1999. Dispõe sobre a educação ambiental, institui a Política Nacional de Educação Ambiental e dá outras providências. Brasília, 1999. Disponível em: http://www.planalto.gov.br/ccivil_03/leis/19795.htm. Acesso em: 05 mar. 2019.

BRASIL. Decreto n. 4.281, de 25 de junho de 2002. Regulamenta a Lei $\mathrm{n}^{\circ} 9.795$, de 27 de abril de 1999, que institui a Política Nacional de Educação Ambiental, e dá outras providências. Brasília: Casa Civil, 2002. Disponível em: http://www.planalto.gov.br/ccivil_03/decreto/2002/d4281.htm. Acesso em: 06 mar. 2019.

BRASIL. Ministério da Educação. Resolução n. 2/2012, de 15 de junho de 2012. Estabelece as Diretrizes Curriculares Nacionais para a Educação Ambiental. Brasília: MEC, 2012. Disponível em: http://conferenciainfanto.mec.gov.br/images/conteudo/iv-cnijma/diretrizes.pdf. Acesso em: 07 mar. 2019.

CASCINO, F. Educação ambiental: princípios, história e formação de professores. São Paulo: SENAC São Paulo, 1999.

CHAPANI, D. T.; CAVASSAN, O. O estudo do meio como estratégia para o ensino de ciências e educação ambiental. Mimesis, Bauru, v. 18, n. 1, p. 19-39, 1997. Disponível em:

https://www.researchgate.net/profile/Daisi_Chapani/publication/322686917_O_Estudo_do_Meio_com o_Estrategia_para_o_Ensino_de_Ciencias_e_Educacao_Ambiental/links/5a68ec504585151ee4d9c9e5 /O-Estudo-do-Meio-como-Estrategia-para-o-Ensino-de-Ciencias-e-Educacao-Ambiental.pdf. Acesso em: 10 jul. 2018.

FAZENDA, I. C. A. Interdisciplinaridade: um projeto em parceria. 6. ed. São Paulo: Loyola, 2007.

FAZENDA, I. C. A. Interdisciplinaridade: história, teoria e pesquisa. 18. ed. Campinas: Papirus, 2011. 
FRIGOTTO, G. A interdisciplinaridade como necessidade e como problema nas ciências sociais. Ideação, Foz do Iguaçu, v. 10, n. 1, p. 41-62, 2008. Disponível em: http://e-

revista.unioeste.br/index.php/ideacao/article/view/4143. Acesso em: 10 mar. 2020.

GUIMARÃES, M. Educação ambiental: no consenso um embate?. 5. ed. Campinas: Papirus, 2007.

GUIMARÃES, M. A Dimensão Ambiental Na Educação. 12 ed. Campinas: Papirus, 2015.

GUIMARÃES, M. Por uma educação ambiental crítica na sociedade atual. Revista Margens Interdisciplinar, Belém, v. 7, n. 9, p. 11-22, 2016. Disponível em: https://periodicos.ufpa.br/index.php/revistamargens/article/view/2767. Acesso em: 27 jan. 2020.

GUIMARÃES, M. et al. Educadores ambientais nas escolas: as redes como estratégia. Cadernos Cedes, Campinas, v. 29, n. 77, p. 49-62, 2009. Disponível em: https://www.scielo.br/scielo.php?pid=S0101-32622009000100004\&script=sci_abstract\&tlng=pt. Acesso em: 20 jul. 2018.

HOUAISS, A. Pequeno Dicionário Houaiss da Língua Portuguesa. 1 ed. Rio de Janeiro: Moderna, 2015.

IVENICKI, A.; CANEN, A. G. Metodologia da Pesquisa: rompendo fronteiras curriculares. Rio de Janeiro: Ciência Moderna, 2016.

LAYRARGUES, P. P. Para onde vai a educação ambiental? O cenário político-ideológico da educação ambiental brasileira e os desafios de uma agenda política crítica contra-hegemônica. Revista Contemporânea de Educação, Rio de Janeiro, v. 7, n. 14, p. 388-411, 2012. Disponível em: https://revistas.ufrj.br/index.php/rce/article/view/1677/. Acesso em: 28 jan. 2020.

LAYRARGUES, P. P.; LIMA, G. F. da C. Mapeando as macrotendências político-pedagógicas da educação ambiental contemporânea no Brasil. In: ENCONTRO PESQUISA EM EDUCAÇÃO AMBIENTAL, 6, 2011, Ribeirão Preto. Anais .... Ribeirão Preto: Universidade de São Paulo, 2011. p. 1-15. Disponível em:

https://www.icmbio.gov.br/educacaoambiental/images/stories/biblioteca/educacao_ambiental/Layrarg ues_e_Lima_-_Mapeando_as_macro-tend\%C3\%83\%C2\%AAncias_da_EA.pdf. Acesso em: 3 fev. 2020 .

LIMA, M. J. G. S. de. Reflexões sobre a prática interdisciplinar da educação ambiental no contexto escolar. REUNIÃO ANUAL DA ANPED, 29, 2006, Caxambu. Anais ... Caxambu: ANPED, 2006. p. 01-06. Disponível em: http://29reuniao.anped.org.br/trabalhos/posteres/GT22-2571--Int.pdf. Acesso em: 14 mar. 2019.

LIMA, M. J. G. S. de. A disciplina Educação Ambiental na Rede Municipal de Educação de Armação de Búzios (RJ): investigando a tensão disciplinaridade/integração na política curricular. 2011. 240f. Tese (Doutorado em Educação) - Universidade Federal do Rio de Janeiro, 2011. Disponível em: https://ppge.educacao.ufrj.br/teses/TESE_JACQUELINE_GIRAO.pdf. Acesso em: 14 mar. 2019.

LIOTTI, L. C. A educação ambiental e o currículo escolar: as diferentes concepções de EA que orientam as práticas escolares. In: CONGRESSO NACIONAL DE EDUCAÇÃO, 13, 2015, Curitiba. Anais... Curitiba: Educere, 2015, p. 3572-3583. Disponível em: https://educere.bruc.com.br/arquivo/pdf2015/18678_7738.pdf. Acesso em: 22 nov. 2018. 
LOUREIRO, C. F. B. Educação ambiental e gestão participativa na explicitação e resolução de conflitos. Gestão em Ação, Salvador, v. 7, n. 1, p. 1-16, 2004. Disponível em:

http://arquivo.ambiente.sp.gov.br/cea/2011/12/FredericoLoureiro.pdf. Acesso em: 17 jul. 2018.

LOUREIRO, C. F. B. Trajetória e Fundamentos da educação ambiental. 2 ed. São Paulo: Cortez, 2006.

LOUREIRO, C. F. B. Premissas teóricas para uma educação ambiental transformadora. Ambiente \& Educação, Rio Grande, v. 8, n. 1, p. 37-57, 2008. Disponível em:

https://periodicos.furg.br/ambeduc/article/view/897. Acesso em: 17 jul. 2018.

MIRANDA, R. G. Da Interdisciplinaridade. In: FAZENDA, I. C. A. (Org.) $O$ Que é interdisciplinaridade?. São Paulo: Cortez, 2008, p. 113-124.

NASCIMENTO, F. N. Aulas de campo: uma proposta para o ensino de ciências que tenha como eixo integrador a educação ambiental crítica. 2015. 155f. Dissertação (Mestrado em Educação em Ciências e Matemática) - Instituto Federal do Espírito Santo, Vitória, 2015. Disponível em: https://repositorio.ifes.edu.br/bitstream/handle/123456789/211/DISSERTA\%c3\%87\%c3\%83O_Aulas _campo_proposta_ensino_ciencias.pdf?sequence=1\&isAllowed=y. Acesso em: 13 fev. 2020.

NASCIMENTO, F. N.; SGARBI, A. D. Educação Ambiental Crítica em Ambientes Costeiros do Estado do Espírito Santo. In: CAMPOS, C. R. P. (Org). Aulas de campo para alfabetização científica: práticas pedagógicas escolares. Vitória: Ifes, 2015. p. 77-104. Disponível em:

https://educimat.ifes.edu.br/images/stories/Publica\%C3\%A7\%C3\%B5es/Livros/Aulas-de-Campopara-Alfabetiza\%C3\%A7\%C3\%A3o-Cient\%C3\%ADfica-978-85-8263-092-1.pdf. Acesso em: 10 fev. 2020.

OLIVEIRA, A. L. de. A perspectiva participativa para inserção da Educação Ambiental Crítica em Escolas da Baixada Fluminense. 2012. 143f. Dissertação (Mestrado em Educação) - Universidade Federal Rural do Rio de Janeiro, Seropédica/Nova Iguaçu, 2012. Disponível em: http://www.agrimensura.ufrrj.br/posgrad/ppgeduc/paginas/docs_dissertacao/2012/AlineOliveira.pdf. Acesso em: 29 jan. 2020.

REIS, H. A. A aula de campo como instrumento de uma educação ambiental transversal almejando a formação de conhecimentos para a sustentabilidade. 2016. 107f. Dissertação (Mestrado Profissional em Ensino em Ciências da Saúde e do Meio Ambiente) - Centro Universitário de Volta Redonda (UniFOA), Volta Redonda, 2016. Disponível em:

https://sites.unifoa.edu.br/portal_ensino/mestrado/mecsma/arquivos/2016/henrique-amaral.pdf. Acesso em: 12 fev. 2020.

SANTOS, E. F. dos. O Processo de Criação da Reserva Biológica do Tinguá: conflitos na constituição de uma Unidade de Conservação, Nova Iguaçu-RJ (1987-1989). 2014. 132f. Dissertação (Mestrado em História Social) - Universidade do Estado do Rio de Janeiro, Rio de Janeiro, 2014. Disponível em: http://www.ppghsuerj.pro.br/ppg/c.php?c=download_dissert\&arq=117. Acesso em: 24 mar. 2019.

SÃO PAULO (Estado). Coordenadoria de Educação Ambiental. Educação ambiental e desenvolvimento: documentos oficiais. São Paulo: Secretaria do Meio Ambiente, 1994.

SAUVE, L. Uma cartografia das correntes em Educação Ambiental. In: SATO, M.; CARVALHO, I. C. M. (Orgs.). Educação Ambiental - pesquisas e desafios. Porto Alegre, Artmed, 2005. p. 17-45. Disponível em:

https://edisciplinas.usp.br/pluginfile.php/4586522/mod_resource/content/1/sauve\%20correntes\%20EA .pdf. Acesso em: 2 fev. 2020. 
TAMAIO, I. A mediação do professor na construção do conceito de natureza: uma experiência de educação ambiental na Serra da Cantareira e Favela do Flamengo-São Paulo/SP. 2000. 152f.

Dissertação (Mestrado em Educação Aplicada às Geociências) - Universidade Estadual de Campinas, Campinas, 2000. Disponível em: http://repositorio.unicamp.br/handle/REPOSIP/287068. Acesso em: 02 fev. 2020.

THIOLLENT, M. Metodologia da pesquisa-ação. 2 ed. São Paulo: Cortez, 1986.

VIVEIRO, A. A. Atividades de campo no ensino das ciências: investigando concepções e práticas de um grupo de professores. 2006. 172f. Dissertação (Mestrado em Educação para a Ciência) Universidade Estadual Paulista, Bauru, 2006. Disponível em:

https://repositorio.unesp.br/bitstream/handle/11449/90877/viveiro_aa_me_bauru.pdf?sequence=1\&isA llowed=y. Acesso em: 12 jul. 2018.

VIVEIRO, A. A.; DINIZ, R. E. da S. Atividades de campo no ensino das ciências e na educação ambiental: refletindo sobre as potencialidades desta estratégia na prática escolar. Ciência em tela, Rio de Janeiro, v. 2, n. 1, p. 1-12, 2009. Disponível em:

http://www.cienciaemtela.nutes.ufrj.br/artigos/0109viveiro.pdf. Acesso em: 26 jun. 2018. 